\title{
Influence of Resource Mismatch Between Industries on Environmental Efficiency

\author{
Yurong Zhang
}

\author{
SILC Business School, Shanghai University, P.R. China \\ Corresponding author.Email:zhangyr4666@163.com
}

\begin{abstract}
Taking 36 subdivided industrial sectors as research samples, this paper empirically analyzes the impact of resource mismatch between industries on environmental efficiency. The results show that resource mismatch between industries will significantly reduce environmental efficiency. Based on the results of empirical analysis, this paper puts forward relevant policy suggestions from the aspects of reducing administrative barriers, reducing credit intervention in the financial field, eliminating biased policies, and gradually removing obstacles to labor mobility, so as to improve the environmental quality of China and realize the coordinated development of environment and economy.
\end{abstract}

Keywords: Resource mismatch, Environmental efficiency, Data Envelopment Analysis, Industrial sectors.

\section{INTRODUCTION}

Since the reform and opening up, China has carried out a series of market-oriented reforms, but most of them focus on the product market, while the market-oriented reform of the factor market lags behind relatively, which leads to the misallocation of resources among different economic sectors and the widespread distortion of the factor market, especially in the industrial sector. The market distortion of industrial factors not only reduces the efficiency of resource allocation, but also further affects the ecological efficiency and aggravates environmental pollution. Facing the environmental problems and energy crisis, the 14th Five-Year Plan adopted at the Fifth Plenary Session of the 19th CPC Central Committee pointed out that we should accelerate the promotion of green and low-carbon development, continuously improve environmental quality, enhance the quality and stability of the ecosystem, and comprehensively improve the efficiency of resource utilization.

Taking 36 industrial sectors as samples, this paper studies the impact of resource misallocation on environmental efficiency. The results show that resource misallocation among industries will reduce environmental efficiency. On the one hand, this study provides the decision-making basis for making the industrial policy of reasonable intensity; On the other hand, it helps strengthen green science and technology research and development, adjust the industrial structure, improve the coordination mechanism between the ecological environment and economic development, and ensure high-quality economic development.
The other parts of this paper are arranged as follows: the second part reviews the literature related to resource mismatch and environmental efficiency; The third part is the measure of resource mismatch degree between industries. The fourth part is the model setting and result analysis, the fifth part is the conclusion and policy suggestions.

\section{LITERATURE REVIEW}

\subsection{Relevant Research On Resource Mismatch}

[1] started the first analysis of enterprise TFP and economic growth from the perspective of resource allocation, and then domestic and foreign scholars carried out a large number of empirical studies from two aspects. For example, [2] analysed the efficiency of interdepartmental capital allocation, and demonstrated that output, technological progress and structural changes are all affected by resource mismatch. If these mismatch factors can be reduced, China's total output level and technological progress level will be improved. In addition,[3],[4] and [5] analysed the impact of resource mismatch on total factor productivity.[6] and [7] point out that the misallocation of intermediate inputs and labour factors among sectors causes huge differences in total factor productivity between countries.[8] analysed the impact of resource mismatch on economic structure and technological progress from the perspective of the impact of the technological level and economic development degree of different trade objects on the resource allocation efficiency of the host country. 
On the other hand, it is a research on the causes of resource mismatch. The existing literature mainly discusses and analyses from the aspects of regulation, taxation, policies, lending constraints and the incompleteness of financial markets.[9] pointed out that compared with other industries, the agricultural sector has obvious preferential policies, which will affect the resource allocation of the whole economy, thus affecting the per capital income level, the change of industrial structure and the speed of economic growth.[10] pointed out that the differential lending of banks to enterprises is an important reason for capital mismatch between enterprises. Because of China's special institutional environment, its resource allocation mode is different from that of other countries.[4] measured the severity of resource distortion in China's manufacturing industry by analysing and decomposing the dispersion degree of total factor productivity, and found that the resource allocation efficiency close to zero in state-owned enterprises is the main factor causing the mismatch of manufacturing resources.[11] used the data of Chinese industrial enterprises from 1998 to 2007 and found that the scale of enterprises had the most significant impact on the distortion of resource allocation.

\subsection{Relevant Research On Environmental Efficiency}

[12] thought that the necessary way to reduce unexpected output should be at the expense of the reduction of the number of normal products. The expected output efficiency is measured by radial measurement, and the pollutant efficiency is measured by reverse measurement. This method can increase the expected output and reduce pollutants in the whole evaluation system.[13] and [14] put forward the input variable method and reciprocal transformation method to measure environmental efficiency. In the input variable method, [13] included the undesired output as a kind of production input in the measurement, and [14] included the undesired output variables in the new method for measurement.[14] put forward the data transformation function method, whose basic idea is to use negative output transformation, nonlinear data transformation and linear data transformation to fundamentally transform the nature of undesired output into desired output, and then put the transformed pollution variables as ordinary expected positive output into the traditional IDEA model which cannot include negative output for calculation.

As for the research on the influencing factors of environmental efficiency,[15] and [16] respectively studied environmental efficiency from the perspectives of energy structure and industrial structure.[17] found that technological progress can affect environmental efficiency through energy efficiency. Some scholars argue that free trade will not have a negative impact on environmental efficiency, and may even encourage environmental improvement. The results of [18] show that trade growth increases the average concentration of pollutants. However, the trade competition brought about by economies of scale and technological progress can stimulate project development, technological innovation and industrial development and pollutant concentration reduction.[19] analysed the impact of trade openness on OECD countries and found that the impact of trade on the environment depends on the characteristics, current situation and pollutant types of each country.

\section{MEASUREMENT OF RESOURCE MISMATCH DEGREE BETWEEN INDUSTRIES}

\subsection{The Measurement Method of Resource Mismatch Degree}

Assuming that there is a perfectly competitive market and resources can flow fully and freely, factors will flow from sectors with low return on investment to sectors with high return on investment to achieve "efficient allocation", while resource misallocation is a deviation from this state. In the real economy, due to the monopoly power, government regulation, market segmentation, foreign trade, asymmetric information and other factors, the free flow of resources is restricted, the economy will deviate from the Pareto optimal state, making the resource mismatch become normal.[1] believed that resource mismatch is reflected by unequal marginal returns among production factors, that is, if the factor input ratio of enterprises does not deviate, then the output and productivity of enterprises are the same, otherwise enterprises can improve the total output by correcting the mismatch of resources. From a macro perspective, the misallocation of resources will lead to the distortion of factor market and hinder the optimization of industrial structure.[20] believe that in developing countries like China, with the change of industrial structure, if factors cannot be effectively allocated, there will be efficiency loss caused by resource mismatch.

Based on the real existence and micro manifestation of resource mismatch, there are two main methods to measure resource mismatch at present. The first is the parametric method, which measures the degree of resource mismatch through the gap between actual total factor productivity and effective total factor productivity. The second is the semi-parametric method, that is, in the competitive environment, the free flow of factors presents a positive correlation between the productivity level and the firm size. The OP method ([21]) is used to decompose the total factor productivity to obtain the OP covariance of resource mismatch. The greater the covariance, the smaller the degree of resource distortion. Referring to [1] and [11], this chapter uses the parametric method to measure the degree of resource distortion. For 
limited space, the specific derivation process is shown in the attachment.

\subsection{Measurement and Analysis of Resource Mismatch Degree In Different Industries}

\subsubsection{Data source and processing}

The original data for measuring resource mismatch comes from the National Bureau of Statistics' "database of all state-owned and non-state-owned industrial enterprises above designated size," which includes all state-owned enterprises and non-state-owned enterprises with sales of more than 5 million yuan. The indicators in this chapter include the industry codes (double digits, for limited space,36 industry codes and names of research and analysis are shown in the attachment), the annual average net value of fixed assets, industrial growth and the total amount of wages payable in the current year of all enterprises from 2000 to 2007.In this part, refer to [22] to reject abnormal values, and the main rejection criteria are as follows:(1)Delete the enterprises whose total assets, fixed assets, industrial added value and wages payable are less than 0 or missing;(2)Delete enterprises with total assets less than current assets or fixed assets;(3)Delete enterprises with fewer than 10 employees;(4)According to the sample range used, the key indicators used were excluded, including enterprises whose industrial added value, annual average net value of fixed assets and total payables of the current year are $0.5 \%$ or less. After removing outliers, nearly 2 million observations including 36 industries were finally obtained.

\subsubsection{Measurement And Analysis Of Resource Mismatch Degree}

According to the hypothesis of [1], we set the elasticity of industrial added value among enterprises as $\sigma=3$, which is a conservative elastic estimation. Since it is impossible to know the real outputYsi, we calculated the real output $\square \mathrm{Y} \rrbracket \_s i=\left(P_{-} s i Y_{-} \text {si }\right)^{\wedge}(\sigma /(\sigma-1))$ based on the income and demand elasticity, then represented Ksi by the net value of fixed assets; represented PsiYsi by the industrial added value; representedwLsi by the total wages payable this year; and substituted the corresponding data into the formula, and the result was the ratio between the actual productivity TFP and the productivity TFP efficient under effective allocation, that is the degree of resource mismatch.

According to the calculation results, the average resource mismatch coefficients of the industry from 2000 to 2007 is $0.420843 、 0.393889 、 0.364196 、 0.471112$ 、 $0.419144 、 0.437714 、 0.51316$ and 0.510612 , respectively. It can be seen that from 2000 to 2002, the overall resource allocation efficiency of the industry declined and the degree of resource distortion increased.
However, from 2002 to 2007, the overall resource allocation efficiency of the industry had been improved, and the flow of factors in the market was more reasonable.

\section{MODEL SETTING AND RESULT ANALYSIS}

\subsection{Measurement of Environmental Efficiency}

Data Envelopment Analysis (DEA) is a cutting-edge efficiency measurement method, DEA method has a remarkable effect in measuring the relative efficiency of multiple input and output decision units (DMU).The method treats different evaluation objects as decision units, and multiple decision units form a decision group, in which each decision unit enjoys the same resources and generates outputs of the same category. That is to keep the input index or output index of different decision units consistent. Based on the mathematical programming model, the relative efficiency of different decision making units can be compared, and the inputoutput ratio can be comprehensively evaluated. Statistical data can be obtained to determine the effective production frontier, and each decision making unit can be projected, so as to obtain the comprehensive efficiency quantitative index of each decision element.

In the research of environmental efficiency measurement by DEA model, the change index of environmental pollution is usually regarded as negative output, and the non-positive change value is given a large enough normal quantity to make it positive, and then it is included in the input-output model. Or take the environmental pollution change index as a negative output, so that the negative change index has weak disposability. Referred to [23], the environmental pollution was taken as the negative output to measure the environmental efficiency of 36 subdivided industries from 2000 to 2007. For limited space, only the calculation results of environmental efficiency of different industries are listed here, and the specific methods are shown in the attachment.

The data of industrial enterprises above designated size are selected to measure environmental efficiency. The original data are from the national statistical yearbook over the years, and the variables used include: (1)Energy input, based on the annual energy consumption of various industries (unit:10,000 tons of standard coal); (2)Labour input, based on the annual average number of employees in each industry as the basic data (unit:10,000 people); (3)Output data: taking the annual gross industrial output value of various industries in China Statistical Yearbook as the basic output data (unit:100 million yuan), and using the exfactory price index of different industries to deflate the output value, the total industrial output value at constant 
price was obtained based on 1990; (4)SO2 emission is selected as the negative output index.

Based on the panel data of each industry, the environmental efficiency of each industry is obtained by using DEA-solver. For limited space, the environmental efficiency values from 2003 to 2007 are listed here, as shown in Table 1.

Table 1. Environmental efficiency values by sector from 2003 to 2007

\begin{tabular}{|c|c|c|c|c|c|c|}
\hline $\begin{array}{l}\text { Industry } \\
\text { code }\end{array}$ & The industrial sector & 2003 & 2004 & 2005 & 2006 & 2007 \\
\hline 6 & Coal mining and washing industry & 0.079 & 0.076 & 0.092 & 0.079 & 0.103 \\
\hline 7 & Oil and gas extraction industry & 0.064 & 0.083 & 0.112 & 0.118 & 0.130 \\
\hline 8 & Mining and dressing industry of ferrous metal ore & 0.238 & 0.244 & 0.389 & 1.000 & 0.155 \\
\hline 9 & Non-ferrous metal mining and dressing industry & 0.276 & 0.282 & 0.281 & 0.254 & 0.494 \\
\hline 10 & Non-metallic mining and dressing industry & 0.200 & 0.163 & 0.200 & 0.122 & 0.231 \\
\hline 13 & Agricultural and sideline food processing industry & 0.433 & 0.429 & 0.402 & 0.406 & 0.491 \\
\hline 14 & Food manufacturing industry & 0.338 & 0.300 & 0.307 & 0.280 & 0.375 \\
\hline 15 & Beverage manufacturing industry & 0.484 & 0.377 & 0.367 & 0.341 & 0.465 \\
\hline 16 & Tobacco products industry & 0.774 & 0.729 & 0.834 & 0.852 & 0.982 \\
\hline 17 & textile industry & 0.254 & 0.232 & 0.211 & 0.205 & 0.220 \\
\hline 18 & Textile clothing, shoes and hats manufacturing industry & 0.674 & 0.607 & 0.573 & 0.561 & 0.614 \\
\hline 19 & Leather,fur,feather(down) and its products industry & 0.847 & 0.747 & 0.767 & 0.708 & 0.801 \\
\hline 20 & $\begin{array}{c}\text { Wood processing and wood, bamboo, rattan, palm and grass } \\
\text { products industry }\end{array}$ & 0.380 & 0.334 & 0.289 & 0.211 & 0.309 \\
\hline 21 & Furniture manufacturing industry & 0.889 & 0.951 & 0.921 & 0.903 & 0.971 \\
\hline 22 & Paper Making and Paper Products Industry & 0.312 & 0.250 & 0.247 & 0.234 & 0.319 \\
\hline 23 & Printing industry and reproduction of recording media & 0.315 & 0.351 & 0.372 & 0.407 & 0.393 \\
\hline 24 & $\begin{array}{l}\text { Cultural, educational and sporting goods } \\
\text { manufacturing industry }\end{array}$ & 0.751 & 0.558 & 0.627 & 0.618 & 0.608 \\
\hline 25 & $\begin{array}{l}\text { Petroleum processing, coking and nuclear fuel } \\
\text { processing industry }\end{array}$ & 0.120 & 0.119 & 0.129 & 0.134 & 0.143 \\
\hline 26 & $\begin{array}{c}\text { Chemical raw materials and chemical products } \\
\text { manufacturing industry }\end{array}$ & 0.108 & 0.109 & 0.107 & 0.103 & 0.111 \\
\hline 27 & Pharmaceutical manufacturing industry & 0.316 & 0.309 & 0.307 & 0.280 & 0.382 \\
\hline 28 & Chemical fiber manufacturing industry & 0.148 & 0.217 & 0.231 & 0.217 & 0.260 \\
\hline 29 & Rubber products industry & 0.255 & 0.202 & 0.196 & 0.150 & 0.204 \\
\hline 30 & Plastic products industry & 0.302 & 0.281 & 0.235 & 0.232 & 0.283 \\
\hline 31 & Non-metallic mineral products industry & 0.213 & 0.164 & 0.148 & 0.156 & 0.173 \\
\hline 32 & Ferrous metal smelting and rolling processing industry & 0.078 & 0.085 & 0.083 & 0.078 & 0.086 \\
\hline 33 & Nonferrous metal smelting and rolling processing industry & 0.208 & 0.207 & 0.181 & 0.184 & 0.181 \\
\hline 34 & Metal products industry & 0.186 & 0.206 & 0.182 & 0.185 & 0.235 \\
\hline 35 & General equipment manufacturing industry & 0.297 & 0.391 & 0.331 & 0.326 & 0.386 \\
\hline 36 & Special equipment manufacturing industry & 0.361 & 0.328 & 0.318 & 0.329 & 0.405 \\
\hline 37 & Transportation equipment manufacturing industry & 0.502 & 0.426 & 0.439 & 0.513 & 0.604 \\
\hline
\end{tabular}




\begin{tabular}{ccccccc}
\hline 39 & $\begin{array}{c}\text { Electrical machinery and equipment manufacturing industry } \\
40\end{array}$ & 0.622 & 0.616 & 0.663 & 0.731 & 0.801 \\
& $\begin{array}{c}\text { Communication equipment, computer and other electronic } \\
\text { equipment manufacturing industry }\end{array}$ & 1.000 & 1.000 & 1.000 & 1.000 & 1.000 \\
41 & $\begin{array}{c}\text { Instrumentation and culture, office supplies machinery } \\
\text { manufacturing industry }\end{array}$ & 0.811 & 0.981 & 0.966 & 0.940 & 0.918 \\
42 & Arts and crafts and other manufacturing industries & 0.104 & 0.118 & 0.120 & 0.126 & 0.149 \\
44 & Production and supply of electricity and heat industry & 1.000 & 1.000 & 1.000 & 1.000 & 1.000 \\
45 & Gas production and supply industry & 0.246 & 0.213 & 0.209 & 0.139 & 0.252 \\
& Mean Value & 0.394 & 0.380 & 0.384 & 0.392 & 0.423
\end{tabular}

According to Table 1, the environmental efficiency value of communication equipment, computer and other electronic equipment manufacturing industry and production and supply of electricity and heat industry are 1 , indicating that these industries are at the forefront and have the highest environmental efficiency. The environmental efficiency value of tobacco products industry; leather, fur, feather(down) and its products industry; furniture manufacturing industry;

instrumentation and culture, office supplies machinery manufacturing industry is greater than 0.7 , and these industries are in the middle of the environmental efficiency value, which is relatively coordinated with the environment in development. The environmental efficiency value of industries such as textile clothing, shoes and hats manufacturing; cultural, educational and sporting goods manufacturing is between 0.5-0.7, which is still far behind the production frontier, and has great potential for improving environmental efficiency.

\subsection{Impact of Inter-industry Resource Mismatch On Environmental Efficiency}

\subsubsection{Data and variable description}

Table 2. Descriptive statistics of each variable
This part uses the panel data of 36 industrial sectors in China from 2000 to 2007. All the data come from the database of industrial enterprises above designated size in China and China Statistical Yearbook. Explained variables are environmental Efficiency index(Efficiency), and explanatory variables are resource mismatch degree and other control variables respectively: (1)ESTR indicates energy structure: expressed by the proportion of terminal coal consumption in different industries to total terminal energy consumption in different industries; (2)IS represents the internal industrial structure of the industry: expressed by the proportion of the total industrial output value of each industry in the sum of the total industrial output value; (3)FDI represents the level of foreign investment: expressed by the proportion of the total industrial output value of industrial enterprises with foreign investment and investment from Hong Kong, Macao and Taiwan in the total industrial output value of industrial enterprises above designated size; (4)AS represents the average scale of the industry: expressed by the ratio of the total output value of industrial enterprises above designated size by industry to the number of enterprises above designated size by industry; (5)R\&D represents technological progress: expressed as energy consumption per unit of GDP of each industry. Descriptive statistical results of each variable are shown in Table 2.

\begin{tabular}{lcccc}
\hline \multicolumn{1}{c}{ Variables } & \multicolumn{5}{c}{ Mean value Standard deviation Minimum value Maximum value } \\
\hline Environmental efficiency (Efficiency) & 0.3948 & 0.2818 & 0.0635 & 1.0000 \\
Resources mismatch (Allocation) & 0.4703 & 0.1801 & 0.0385 & 0.8019 \\
Energy structure (ESTR) & 0.6814 & 1.1229 & 0.0626 & 7.1408 \\
Internal industrial structure (IS) & 0.3545 & 0.9210 & 0.0019 & 6.1016 \\
Foreign capital level (FDI) & 0.2855 & 0.1850 & 0.0023 & 0.8414 \\
Industry average size (AS) & 2.5736 & 6.6639 & 0.2515 & 45.1090 \\
technology progress $(R \& D)$ & 0.7304 & 0.6776 & 0.0683 & 3.0893 \\
\hline
\end{tabular}




\subsubsection{Model And Parameter Estimation}

Set the panel data measurement model as follows:
In the Equation(1), represents the industrial sector, represents the year, $\beta \_0 \sim \beta \_6$ are the parameters to be estimated, $\mu$ is an unobservable random interference term. The regression results are shown in Table 3.

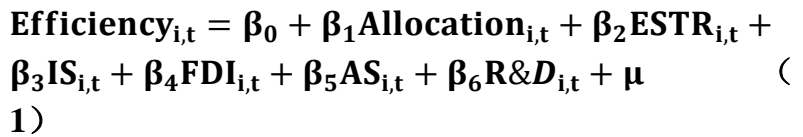

Table 3. Measurement results of the correlation between resource mismatch and environmental efficiency

\begin{tabular}{|c|c|c|c|c|}
\hline & (1) & (2) & (3) & (4) \\
\hline & Fixed & Fixed & Fixed & Random \\
\hline \multirow[t]{2}{*}{ Allocation } & $0.0379^{* *}$ & $0.0213^{* *}$ & $0.0372^{* *}$ & $0.0165^{*}$ \\
\hline & $(0.0155)$ & $(0.0094)$ & $(0.0170)$ & $(0.0086)$ \\
\hline \multirow[t]{2}{*}{ ESTR } & $-0.134^{* * *}$ & $-0.104^{* * *}$ & $-0.126^{* * *}$ & $-0.102^{* * *}$ \\
\hline & $(0.0464)$ & $(0.0252)$ & $(0.0473)$ & $(0.0250)$ \\
\hline \multirow[t]{2}{*}{$I S$} & -0.00431 & 0.00259 & 0.00374 & -0.00182 \\
\hline & $(0.00648)$ & $(0.00859)$ & $(0.00853)$ & $(0.00623)$ \\
\hline \multirow[t]{2}{*}{$F D I$} & 0.0726 & $0.432^{* * *}$ & -0.00327 & $0.422^{* * *}$ \\
\hline & $(0.210)$ & $(0.160)$ & $(0.251)$ & $(0.147)$ \\
\hline \multirow[t]{2}{*}{$A S$} & 0.00514 & 0.00426 & 0.00526 & 0.00328 \\
\hline & $(0.00363)$ & $(0.00312)$ & $(0.00381)$ & $(0.00300)$ \\
\hline \multirow[t]{2}{*}{$R \& D$} & $0.100^{* * *}$ & $0.152^{* * *}$ & $0.115^{* * *}$ & $0.139^{* * *}$ \\
\hline & $(0.0320)$ & $(0.0279)$ & $(0.0356)$ & $(0.0258)$ \\
\hline Industry fixed & Yes & No & Yes & No \\
\hline Year fixed & No & Yes & Yes & No \\
\hline \multirow[t]{2}{*}{ Constant } & $0.327^{* * *}$ & $0.315^{* * *}$ & $0.382^{* * *}$ & $0.290^{* * *}$ \\
\hline & $(0.0884)$ & $(0.0776)$ & $(0.103)$ & $(0.0720)$ \\
\hline $\mathrm{N}$ & 288 & 288 & 288 & 288 \\
\hline $\mathrm{R}^{2}$ & 0.2304 & 0.2422 & 0.2651 & 0.2088 \\
\hline
\end{tabular}

Note: The standard error is in brackets.* represents $\mathrm{p}<0.10, * *$ represents $\mathrm{p}<0.05, * * *$ represents $\mathrm{p}<0.01$.

Table 3 shows the parameter estimation results of the econometric model, column (1) - (3) are the regression results of fixed industry effect, fixed time effect and time industry double fixed, respectively. Column (4) is the estimation results of random effects model. The estimated results showed that the coefficient of variable Allocation, which measures resource mismatch, is significantly positive in each of the regression rows, indicating that the more severe resource mismatch (namely the lower the ratio of actual productivity TFP to productivity TFP efficient under effective allocation), the lower the environmental efficiency. The results shows strong robustness in both fixed and random effects regression. In addition, among the control variables, the coefficient of energy structure variable expressed by the proportion of coal consumption is significantly negative, indicating that the higher the proportion of coal consumption, the lower the environmental efficiency. The coefficient of $R \& D$ variable representing technology level is significantly positive, indicating that the improvement of technology level is conducive to the improvement of environmental efficiency.

\section{CONCLUSION AND POLICY SUGGESTIONS}

Resource misallocation will have a negative impact on the ecological environment by inhibiting energy utilization rate, hindering the improvement of enterprise productivity, and inhibiting the upgrading of industrial structure. This paper uses the panel data of China's industrial sectors from 2000 to 2007 to empirically 
analyse the impact of resource mismatch between industries on environmental efficiency. The results show that the mismatch of resources among industries will reduce the environmental efficiency. Therefore, based on the empirical analysis results of this chapter, we will reduce the degree of resource mismatch from the aspects of eliminating labour mismatch, financial mismatch and capital mismatch, and put forward the following policy suggestions for improving environmental quality.

Firstly, lower administrative barriers, reduce monopoly of departments and industries, and allow private capital to enter more industrial sectors. In order to reduce the degree of capital distortion and improve the efficiency of capital allocation, it is necessary to expand the industrial opening and realize the free entry and exit, weaken the monopoly power, and form a more fair competition environment.

Secondly, reduce credit intervention in the financial sector and improve the independence of bank credit decision-making, it is suggested that the government-led investment and financing system with financial monopoly should be reformed to reduce financial repression, promote the flow of capital among different departments, enterprises and regions, establish a multilevel and fair financial market system, promote the optimization of industrial structure and improve the environmental quality. Besides, eliminate biased policies and establish a fair competitive environment. Preferential policies will cause the loss of resource allocation efficiency, for example, preferential government subsidies cause the resource mismatch among enterprises. The government should improve the financial subsidy system, make clear the standards that the objects of financial subsidies need to meet, and restrict and standardize the rational use of financial subsidies through the system, so as to eliminate the bias of financial subsidies and make the capital more effectively allocated.

Thirdly, gradually remove obstacles to labour mobility and improve the allocation efficiency of the labour market. In the process of regional and interindustry mobility, China's labour force is faced with constraints such as system, household registration and social security. In view of the problem of labour mismatch, on the one hand, we should increase the investment of human capital and improve the proportion of high-end technical talents; on the other hand, for the industries with surplus labour, it is necessary to increase the appropriate substitution of capital for labour to improve labour productivity.

\section{REFERENCES}

[1] Hsieh C T, Klenow P J. Misallocation and manufac turing TFP in China and India[J]. The Quarterly jou rnal of economics, 2009, 124(4): 1403-1448. DOI: https://doi.org/10.1162/qjec.2009.124.4.1403

[2] Yao,Z.Q. Productivity growth and factor reconfigur ation effect: China's empirical study [J]. Economic Research,2009,44(11),130-143(In Chinese). DOI: CNKI: SUN: JJYJ.0.2009-11-014

[3] Chen, Y.W., Hu,W.M. Price distortion, factor mism atch and efficiency loss: theory and application [J]. economics (quarterly),2011,10(04),1401-1422(In C hinese). DOI: CNKI: SUN: JJXU.0.2011-04-012

[4] Nie,H.H.,Jia R.X. Productivity and Misplacement o f Resources in Chinese Manufacturing Enterprises [ J]. World Economics,2011,34(07),27-42(In Chines e). DOI: CNKI: SUN: SJJJ.0.2011-07-005

[5] Luo, D.M., Li, Y., Shi,J.C. Factor Market Distortio n, Resource Misplacement and Productivity [J]. Ec onomic Research,2012,47(03),4-14+39(In Chinese) . DOI: CNKI: SUN: JJYJ.0.2012-03-003

[6] Restuccia D, Yang D T, Zhu X. Agriculture and ag gregate productivity: A quantitative cross-country a nalysis[J]. Journal of monetary economics, 2008, 5 5(2): 234-250. DOI: https://doi.org/10.1016/j.jmo neco.2007.11.006

[7] Alfaro L, Charlton A, Kanczuk F. Plant-Size Distri bution and Cross-Country Income Differences[J]. S SRN Electronic Journal, 2008, 5(14060):243-272. DOI: https://doi.org/10.2139/ssrn.984471

[8] Banerjee A V, Moll B. Why does misallocation per sist? [J]. American Economic Journal: Macroecono mics, 2010, 2(1): 189-206. DOI: https://doi.org/10. 1257/mac.2.1.189

[9] Dennis B N, İşcan T B. Agricultural distortions, str uctural change, and economic growth: A cross-cou ntry analysis[J]. American Journal of Agricultural E conomics, 2011, 93(3): 885-905.DOI:https://doi.or $\mathrm{g} / 10.1093 / a j a e / a a r 011$

[10] Peek J, Rosengren E S. Unnatural selection: Perver se incentives and the misallocation of credit in Japa $\mathrm{n}[\mathrm{J}]$. American Economic Review, 2005, 95(4): 114 4-1166. DOI: https://doi.org/10.1257/00028280548 25691

[11] Shao, Y.H., Bu, X.N., Zhang,T.H. Distortion of res ource allocation and total factor productivity of Chi na's industry: re-measurement based on industrial e nterprise database $[\mathrm{J}]$. China Industrial Economics2 013, (12),39-51(In Chinese). DOI: CNKI: SUN: G GYY.0.2013-12-005

[12] Färe R, Grosskopf S, Lovell C A K, et al. Multilate ral productivity comparisons when some outputs ar e undesirable: a nonparametric approach $[\mathrm{J}]$. The re 
view of Economics and Statistics, 1989,71(1):90-98 . DOI: https://doi.org/10.2307/1928055

[13] Hailu A, Veeman T S. Non-parametric productivity analysis with undesirable outputs: an application to the Canadian pulp and paper industry[J]. American Journal of Agricultural Economics, 2001, 83(3): 60 5-616. DOI: https://doi.org/10.1111/0002-9092.00 181

[14] Zhu J. Quantitative Models for Performance Evalua tion and Benchmarking: Data Envelopment Analysi $\mathrm{s}$ with Spreadsheets and DEA Excel Solver [M]. K1 uwer Academic Publishers, 2003.

[15] Huang, Y.C., Shi,Q.P. Study on regional environme ntal efficiency and environmental factors in ChinaBased on SBM model including R\&D input [J].Chi na population resources and environment,2015,25( 12),25-34(In Chinese). DOI: 10.3969/j.issn.1002-2 104.2015.12.004

[16] Hu, D.S., Li,Y. Regional differences of environmen tal efficiency evaluation and its influencing factors [J]. Financial Science,2012, (04),116-124(In Chine se). DOI: 10.3969/j.issn.1000-8306.2012.04.014

[17] Li, J.Y. Convergence Analysis of Inter-provincial E nergy Efficiency in China [J]. statistics and decisio n,2012, (02),106-108(In Chinese). DOI: CNKI: S UN: TJJC.0.2012-02-033

[18] Antweiler W, Copeland B R, Taylor M S. Is free tra de good for the environment? [J]. American econo mic review, 2001, 91(4): 877-908. DOI: https://doi. org/10.1257/aer.91.4.877

[19] Managi S, Hibiki A, Tsurumi T. Does trade openne ss improve environmental quality? [J]. Journal of e nvironmental economics and management, 2009, 5 8(3): 346-363.DOI: https://doi.org/10.1016/j.jeem. 2009.04.008

[20] Restuccia D, Rogerson R. Policy distortions and ag gregate productivity with heterogeneous establishm ents[J]. Review of Economic dynamics, 2008, 11(4 ): 707-720. DOI: https://doi.org/10.1016/j.red.2008. 05.002

[21] Olley G S, Pakes A. The Dynamics of Productivity in the Telecommunications Equipment Industry[J]. Econometrica: Journal of the Econometric Society, 1996: 1263-1297. DOI:https://doi.org/10.2307/217 1831

[22] Feenstra R C, Li Z, Yu M. Exports and credit const raints under incomplete information: Theory and ev idence from China[J]. Review of Economics and St atistics, 2014, 96(4): 729-744. DOI: https://doi.org/ 10.1162/REST_a_00405
[23] Liu Y,Li Z.X.,Li Comparative Study on Evaluation Methods of Environmental Efficiency [J]. Mathem atics Practice and Cognition, 2010, 40(01): 84-92(I n Chinese). DOI: CNKI: SUN: SSJS.0.2010-01-00 9 